\title{
Por uma sociologia imaginativa: o presente do passado no processo de cristalização cultural
}

For an imaginative sociology: the present of the past in the cultural crystallization process

\author{
Manuela Eugênio Maia \\ Doutora em Ciência da Informação \\ Universidade Estadual da Paraíba \\ manuelamaia@gmail.com \\ Jacqueline Echeverría Barrancos \\ Doutora em Administração \\ Universidade Estadual da Paraíba \\ unijacqueline@gmail.com
}

\section{Resumo}

O objetivo deste artigo é analisar o processo de cristalização cultural no âmbito da memória coletiva para a Ciência da Informação a partir da abordagem da sociologia imaginativa. O método se dá a partir da analítica filosófica foucaltiana, interpretou-se práticas do vivido, enquanto experiências do cotidiano, e de discursos difundidos no Facebook, estabelecendo reflexões acerca dos processos de cristalização cultural à luz da sociologia imaginativa. Como resultado, percebe-se que a cristalização cultural é um movimento que pode promover falaciosa narrativa harmônica e de retorno ao passado. A memória coletiva, quando usada para respaldar um processo de purificação cultural, pode comprometer o pensamento social e científico em uma configuração linear. O vivido e suas ações cotidianas podem trazer consequências no contexto da marginalização e da própria construção da ciência. Conclui-se, seguindo a citada perspectiva sociológica, que é fundamental superar a noção de harmonia, de artificialidade parcial e tendenciosa e de compreensão de hierarquização das ciências. Esse processo de cristalização cultural para a Ciência da Informação pode se dar por meio da analítica da sociologia imaginativa e do uso estratégico o fenômeno do "entranhamento", tratando-se de uma perspectiva pautada na contraposição do dual e da fragmentação.

\section{Palavras-Chave}

Sociologia imaginativa. Memória social. Cristalização cultural.

\section{Abstract}

The purpose of this article is to analyze the process of cultural crystallization within the scope of collective memory for Information Science from the perspective of imaginative sociology. The method is based on foucaltian philosophical analytics, practices of the lived were interpreted, as everyday experiences, and of discourses disseminated on Facebook, establishing reflections about the processes of cultural crystallization in the light of imaginative sociology. As a result, it is clear that cultural crystallization is a movement that can promote a fallacious harmonic narrative and return to the past. Collective memory, when used to support a process of cultural purification, can compromise social and scientific thinking in a linear configuration. The lived and its daily actions can have consequences in the context of marginalization and the construction of science itself. Concluded, following the aforementioned sociological perspective, it is essential to overcome the notion of harmony, partial and biased artificiality and understanding of the hierarchy of sciences. This process of cultural crystallization for Information Science can happen through the analysis of imaginative sociology and the strate- 
gic use of the phenomenon of "entrenchment", being a perspective based on the opposition of the dual and of fragmentation.

\section{Keywords}

Imaginative sociology. Social memory. Cultural crystallization.

\section{INTRODUÇÃO}

No circuito universitário-acadêmico, nós, seres humanos, somos caçadores de problemas. Vivemos em busca deles e não são poucos; percebemos que há uma pluralidade acerca dos problemas na área social. Os objetos de estudo que tal área abarca envolvem o ser humano e o seu entorno. Ainda que possamos incorporar o não-humano nesse circuito, atentamos que há um processo relacional entre humano e não-humano e, se estes existem ou são nominados, é porque há uma nítida ação humana. Ao nominar as coisas ou os nãohumanos, partimos da linguagem, indiscutivelmente, elemento produzido pelo homem.

Lembramos de uma passagem em que Gaarder (1995) narra algo do tipo: os humanos, quando se tornam adultos, tendem a se desencantarem com mundo e com as suas coisas e, por isso, os entendem como algo natural. Contrariando essa percepção, as crianças tudo perguntam, pois o mundo está sendo explorado e disso resulta o seu constante encantamento. Ao final do trecho desse capítulo, Gaarder (1995) defende que nascemos filósofos e com os fatores "tempo" e "imposição sociocultural" perdemos a capacidade de questionar.

Rememorando essa passagem, começamos a olhar mais a nossa volta e perceber, entre o nosso presente distante a o nosso passado atual, situações que pudessem ser compreendidas como uma questão a ser refletida nessas linhas.

Partindo do real, narramos dois momentos vividos e que possuem uma inquietante questão: o perigoso discurso da cristalização das manifestações culturais, enquanto prática social, o que entendemos como exacerbado processo de purificação do mundo. Isso se apresenta para nós como um olhar romântico de retorno ao passado, como se este fora perfeito. Com tamanha beleza, certamente, para uns, suas práticas culturais não podem ser alteradas! O passado seguiria como sendo um "ente" balizador entre o presente e o futuro. Para uns, isso pode representar uma tola narrativa, mas, para nós, esconde um discurso tão falacioso quanto falso e, quiçá, perigoso, pois está incutido a negativa do avanço e da transformação, gerando uma narrativa de que o passado é espetacular e devesse ser conservado inalteradamente. Atualmente, entre 2018 e 2020, a narrativa do retorno à ditadura militar é incitada nas ruas brasileiras por grupos de extrema direita (O GLOBO, 2020; OLIVEIRA, 2020). Eis a ameaça à democracia.

Assim como uma "criança", tendo mais atenção ao mundo e as suas relações, percebemos uma aproximação entre dois eventos que nos fizeram refletir sobre o que foi posto até o momento. A primeira situação aconteceu num fato cotidiano de uma das autoras. Sua filha, que está matriculada no 3. ano do ciclo fundamental, chegara da escola inquietante e disse: "mãe, a tia [professora] não respeitou a minha resposta na prova história; mandou-me apagar a resposta e colocar a dela!". Curiosa, a criança foi indagada pela mãe do que se tratava. E ela falou: "a pergunta da prova foi 'onde você acha que o índio deve morar?' e a criança respondeu que 'em qualquer lugar, casa, apartamento ou oca'. Mas a professora insistiu dizendo que estava errada e mandou escrever a palavra 'oca'". Inquietando-nos, percebemos que o olhar da docente revelava-se cristalizada, certamente, imposta pela escola e pelo livro didático, como se índio fosse escravo de seu passado e não pudesse prover outras 
formas de vida. Isso nos conduziu a refletir sobre a tendência da cristalização de práticas culturais que "os brancos" determinam. Incomoda-nos perceber até que ponto são escolhidas e como são apresentadas as representações humanas destoantes do que é considerado convencional e, no caso, do índio, é o estereótipo do humano, transmitindo a falsa ideia de cultura imutável e isolada.

Outro evento ocorreu há uns oito anos, em 2006, em reunião de grupo de estudo na Universidade Federal da Paraíba (UFPB), quando uma colega criticava tempestivamente as modificações ocorridas em manifestação cultural situada em Cabedelo, cidade do estado da Paraíba, a Nau Catarineta. Ela contestava a incorporação de elementos tecnológicos na apresentação da dança com o uso de microfone. Insistia na condenação da inclusão de qualquer coisa que trouxesse alterações à origem da manifestação. Naquele momento, dissemos que o mundo muda e o humano também e, aproveitando o ensejo, fizemos três indagações: existe algo puro nas expressões culturais? Você é a mesma pessoa que há dez anos? Por que acorrentar os outros ao passado?

Diante dessas duas experiências, ocorridas num interstício de quase uma década, e estabelecendo um diálogo com a Ciência da Informação $(\mathrm{Cl})$ em seu viés da memória, questionamos como cerne dessa pesquisa: qual é a nossa postura, enquanto pesquisadores da $\mathrm{Cl}$, frente à purificação cultural? Nessa direção, o objetivo do estudo é analisar o processo de cristalização cultural no âmbito da memória coletiva para a Ciência da Informação a partir da abordagem da sociologia imaginativa, que tem perspectiva de lançar olhar diferenciado e mais amplo do habitual acerca dos problemas envolvendo as experiências cotidianas.

\section{PROCEDIMENTOS METODOLÓGICOS}

Ancoradas na analítica filosófica foucaltiana (FOUCAULT, 1987; 2000), baseamo-nos em fatos do presente vivido e em situações disponibilizadas em redes sociais acerca de narrativas envolvendo a cristalização cultural enquanto prática cotidiana e, por vezes, não refletida pelos sujeitos; trata-se de uma pesquisa social crítica.

Sob esse aspecto, para apontar possibilidades acerca dessa questão, a análise utilizada foi pautada na leitura e na discussão filosófica e sociológica que se posiciona na contramão da concepção cristalizadora da cultura e da memória. Por isso, utilizamos da literatura voltada para uma vertente denominada imaginativa, cujos expoentes são: (a) Latour (1994) e Law (1994) na perspectiva da teoria Ator-Rede (TAR), quando propõem estudo acerca da simetria entre humano e não humano (objetos, animais, fenômenos natureza etc) e como essas interações produzem processos sociais e de "entranhamento"; (b) Wagner (2006): critica a percepção de objetificação e de intelectualização sobre a cultura; o olhar sobre esta implica num posicionamento simbólico e inventivo por parte do pesquisador.

Nessa perspectiva reflexiva sobre a descrição da realidade, atentamos que, embora defendamos nossa análise filosófica específica, sabemos que não há um único modo de interpretar, mas várias maneiras e Orlandi (1998, p. 147) comenta:

não há sentido sem interpretação, e a interpretação é um excelente observatório para se trabalhar a relação historicamente determinada do sujeito com os sentidos, em um processo em que intervém o imaginário e que se desenvolve em determinadas situações sociais.

Nesse sentido, o discurso emitido representa uma visão de mundo; trata-se de uma apropriação social. Retomando a discussão acima, as condições de produção intelectuais e 
materiais dos sujeitos estão relacionadas aos elementos históricos dos quais participam. Ainda é procedente argumentar que o referido sujeito condiciona e ao mesmo tempo é condicionado por sua cultura, que se dá em temporalidade e em espaços determinados; é individual na sua existência e é coletivo em sua essência humana (FOUCAULT, 2000).

Essa essência que reflete a humanidade refere-se à ação humana como uma atividade que se organiza em torno de finalidades no âmbito da realidade histórica do sujeito concreto. Ao se relacionar com os objetos e seu constitutivo no mundo, a linguagem, o sujeito estabelece sentido a partir do contato com os outros homens. Portanto, o agir humano emana de experiências sociais (FOUCAULT, 1987).

Também esclarecemos que baseamo-nos numa escrita pautada na coerência lógica do pensamento e na capacidade de aplicar comparações. Coadunando com Schopenhauer (2017, p. 84-85, 92), um bom estilo "é que se tenha algo a dizer, [do contrário, revela] pobreza de pensamento, de espírito e de conhecimento".

Operar com a metodologia da leitura e da interpretação constitui um desafio, pois cada leitor participa da cultura em um dado momento histórico. É buscar no mecanismo de reflexão filosófica seu componente histórico, em que o sujeito que interpreta, compreenda o seu olhar à luz de suas condições presentes.

Segundo Orlandi (2001), analisar um texto oral ou impresso não significa somar as suas frases, tão pouco se trata de um estudo fechado em si. Ao analisar um texto, é necessário perceber suas possibilidades à medida que recortamo-lo e reestabelecemos a relação entre suas partes e o todo, observando a sua totalidade e o seu contexto.

\section{O PASSADO SEMPRE PRESENTE: DA PRÁTICA À SOCIOLOGIA IMAGINATIVA NO PROCES- SO DE CRISTALIZAÇÃO CULTURAL}

A problematização que envolve este estudo repousa em dois elementos significativos: (1) a falsa ilusão que possuímos em pensar que o "nosso" modo de ver e perceber o mundo é o correto e (2) as práticas do passado são sempre melhores que a do presente. Em relação ao primeiro ponto, refere-se a uma necessidade de verdade que nos parece nascermos impregnados dela. Instigante, por certo, pois o pensamento científico tenta se sobressair aos demais (religioso, mítico), discutindo o próprio discurso da verdade e sua pluralidade. Quanto ao segundo aspecto, repousa o antagônico discurso da ciência que se revela esmagador dentro do seu próprio universo: da hierarquia entre ciências puras ou exatas em relação às ciências humanas e, em seu interior, os microgrupos de cientistas que ditam quem deve ou não publicar ou participar da elite científica; ditam quais enunciados são verdadeiros.

Crítica, Pombo (2003) atenta para o discurso que edificou o estatuto da ciência moderna. Começou em suas origens de modo democrático e, ao longo das décadas, sofreu excessos chegando ao ponto de extrema institucionalização, ou seja, cristalização dos modelos e conceitos. Para além disso, a acirrada competitividade entre as diferentes comunidades destoa do sentido, ou melhor, do discurso que acreditamos ser a essência da ciência: estar presente na produção de saberes voltados para o bem comum e para a qualidade da vida humana. Ao contrário desse norte, Pombo $(2003$, p. 8) adverte que, ao longo de sua história, a competitividade entre tais comunidades foi crescente, ao ponto darem-se as "costas voltadas umas para as outras, grupos rivais que lutam para arranjar espaço para o seu trabalho, que competem por subsídios, que estabelecem entre si um regime de concorrência completamente avesso àquilo que era o ideal científico da comunicação universal". O que inicial- 
mente se propunha a trabalhar em prol do desenvolvimento da vida, da humanidade e da terra, revela-se, ao assumir papel de soberania e de aceitação quase que unânime no seio social, desigual e compromissada com grupos de interesse dos mais diversos.

Em relatório da Organização das Nações Unidas para Educação, Ciência e Cultura (UNESCO), é incontestável o papel da ciência no mundo moderno e a sua fundamental relevância na consolidação e sobrevivência do modo de produção capitalista. O mais interessante é a limitação do escopo de ciência, atrelada às tecnologias digitais (banda larga, internet e telefones celulares) e suas consequências, a exemplo da regulação dos "fluxos comerciais [internacionais, dos] direitos de propriedade intelectual, [da] transferência de tecnologia [em] licenças e outros modos de difusão formal e informal de conhecimento" (UNESCO, 2010 , p. 5). Curioso é verificar quais são as áreas de investimento que são consideradas científicas, a saber, "biologia, engenharia e tecnologia, física, matemática, medicina clínica, pesquisa biomédica, química e terra e espaço" (UNESCO, 2010, p. 13). É perceptível a exclusão da área de humanas na qualidade de importante produtor de tecnologia social para o seu desenvolvimento. Ademais, os conflitos de interesse e de financiamento no interior de cada área e subárea de conhecimento, entre universidades e departamentos de pesquisa distorcem, ou melhor, deslocam o porquê da ciência e o seu verdadeiro e primeiro papel.

A institucionalização da ciência conduz para o que Santos (1996) denomina de "indústria da ciência". Esse fenômeno se intensificou no período pós-segunda guerra entre os Estados Unidos da América (EUA) e União das Repúblicas Socialistas Soviéticas (URSS), onde o Estado passa a determinar as políticas científicas - economia e militarismo. Assim, passouse a delimitar o que era ciência de ponta e proletária, fortalecendo o fosso entre países ricos e pobres em função de critérios de industrialização e cientificidade. Como também na perspectiva interna da ciência, produz um escalonamento: as áreas de ponta, que canalizam a maior parte dos recursos e investimento, e o revés, as que lutam para se manter no rol de ciência. $\mathrm{O}$ seu auge é visualizado no circuito de patentes, que estabelece um pertencimento sobre o saber; o mesmo acontece com a produção dos artigos, pesados como batatas quanto mais, melhor! Sem dúvida, um retrocesso científico.

Retomando a questão entorno dos grilhões do passado, dos quais estamos presos, ilustramos com imagens frequentemente postadas no Facebook, uma das maiores redes sociais do mundo na atualidade. Tais imagens servem para demonstrar, em certa medida, a apologia ao passado como se tudo dele fora o certo em detrimento das práticas culturais do presente.

A figura 1 remete a um tipo de educação doméstica em que vigorava o castigo físico como forma de educar. Fortalece o discurso que a "boa" educação é aquela de anos anteriores, em que predominava as penalidades corporais; apresenta a ilusão de que não se falava palavras ofensivas ou se respeitava os mais velhos de forma incontestável. Interessante é que a figura 1 ainda associa ao "bom cidadão" à subserviência, como se não tivesse existido em cada tempo histórico da humanidade rupturas e críticas: 
Figura 1 - Se você se lembra disso...

\section{SE VOCÊ SE LEMBRA DISSO..}

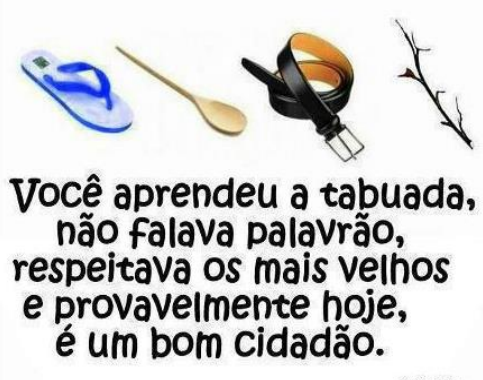

Fonte: AVPRODUCTIONS, [21--].

Na figura 2, reforça o discurso que estabelece apologia a uma prática educativa ou social exercida no passado, mais uma vez, tendo como referência a ação pedagógica. É importante reforçar que o discurso é entendido como um conjunto de práticas, ações, processos, dizeres e fazeres em uma dada cultura ou contexto social que imprime formas de como estão representados os sentidos das coisas, dos sujeitos e de suas relações no mundo (FOUCAULT, 2000). Essa impressão tenta se sobressair a outras e, por isso, o discurso estabelece relações de poder.

Observamos que a figura 2 não apresenta imagens explícitas de objetos que se relacionam a punição física como revelado na figura 1 , que deixa clara essa necessidade para a docilização dos corpos (FOUCAULT, 2002) com o uso de chinelo, colher de pau, cinto ou vara de açoite. Contudo, a agressividade é percebida pelas reações faciais e gesticulares do adulto e, no caso da criança, o discurso corporal apresenta-se claramente subordinado e constrangido, percebida pela cabeça baixa e curvatura da coluna. Mais uma fez as imagens (figuras 1 e 2) reforçam as práticas educacionais de um passado inconteste:

Figura 2 - Sou de uma época...

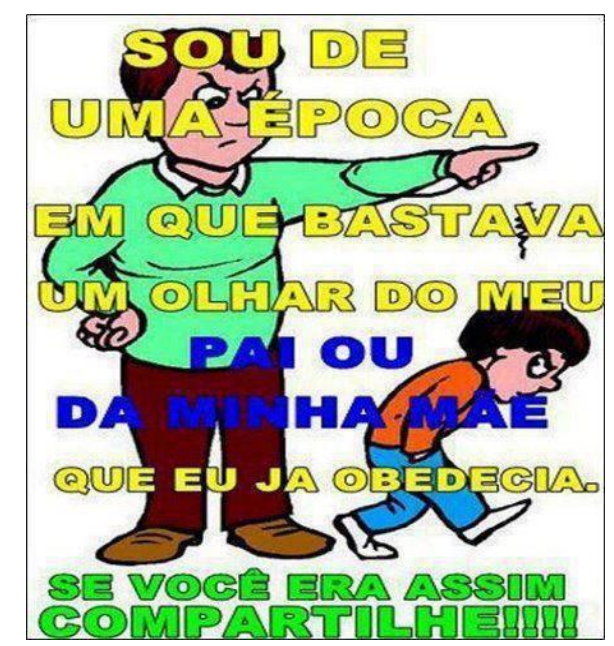

Fonte: ESTILO, [21--].

Reforçando a concepção do passado como sendo algo a ser reproduzido plenamente, a figura 3, para além do expressivo texto que afirma veementemente "isso é infância", 
apresenta os registros imagéticos que ilustram por meio de signos quais representam tais brincadeiras de criança. Sobre isso, baseando-se em Foucault (1987), podemos esclarecer que os testemunhos representam comportamentos culturais passados e contribuem para a compreensão da dinâmica sociocultural de quem os produziu, fazendo com que o processo de registro se estabeleça e seja reconhecido, pois se configura como um sistema simbólico, permitindo ao sujeito se perceber e se incluir nessa atmosfera (AZEVEDO NETTO, 2007).

Longe desse texto denegrir ou defender o contradisurso de negativa ao passado. Nosso intento é que refletamos acerca do que é defendido como metáfora do passado e tecer crítica a romântica visão que o cerca. Ou ainda, uma mentalidade caucada no retorno passado pode encobrir discursos perigosos à liberdade e à democracia, momento pelo qual o Brasil vive.

Figura 3 - Isso sim, se chama infância...

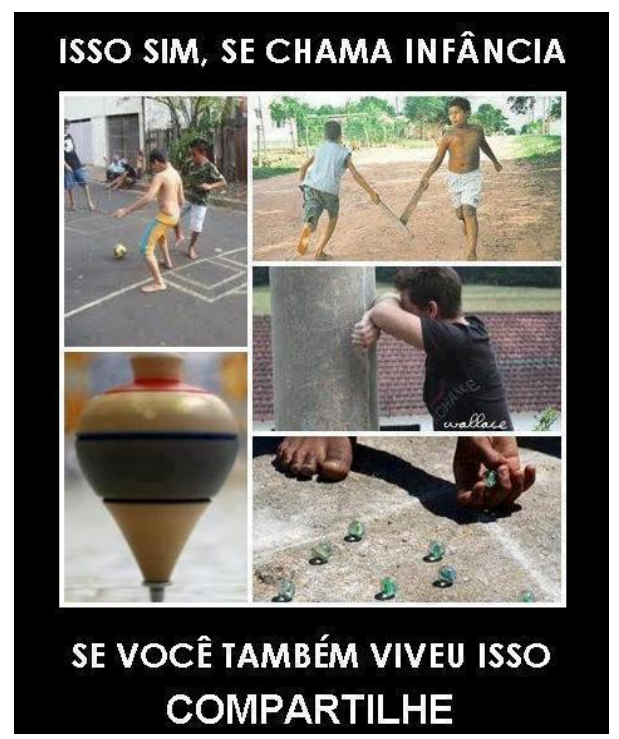

Fonte: MC GUI, [21--].

Aceitar o passado pelo passado evidencia a falta de ponderação das marcas contextuais do presente, que explica ou nos faz perceber os motivos que levaram a minimização ou extinção de determinadas ações ou discursos no presente. Isso explica de modo direto o motivo pelo qual não o vivenciamos mais e, por isso, não participam das práticas do hoje. Considerando o quão é dinâmica a sociedade, é possível a reincorporação de certos discursos a posteriori, podendo ser retomados, funcionando num movimento de "idas e vindas" e de novos e de velhos elementos que se configuram e reconfiguram.

Nesse sentido, Mintz (2010) acrescenta: somos seres de cultura que se comunicam, interagem e compõem-se de elementos endógenos e exógenos a ela. Esse processo é intenso e contínuo, denominado pelo autor supra de "circularidade cultural". Ou seja, não há meio, começo ou fim nas coisas do mundo, o que inclui humanos e não-humanos (tecnologia, natureza e objetos). Essa percepção, a de circularidade, rompe com a secular visão linear que é entendida enquanto sucessão de fatos sem articulação entre os fenômenos, os eventos sociais, a cultura, o mundo e os seus objetos e símbolos. Essa circularidade não possui um marco ou um "ponto zero". Sua lógica é a de que os seus produtos culturais vêm e vão e retornam a sociedade sempre, só que, (res)significados (ASSMANN, 2011).

Nessa direção, Mintz (2010) argumenta que a cultura nos influencia a cada minuto e constantemente. À medida que os humanos adquirem experiências e as acionam, processam 
e são processados enquanto agem. Somos seres de (res)significação, ou seja, nosso comportamento e práticas são mediados por meio de símbolos. Por isso, podemos inferir que a cultura e o seu contexto, a sociedade, por serem produtos humanos, adquirem o estatuto de elementos simbólicos.

Assim, ao nominarmos e ao atribuirmos sentido aos objetos do mundo, segundo Azevedo Netto (2007), estes passam a assumir a categoria de testemunho. Uma vez que tais testemunhos estejam para além da significação imediata do objeto e passam a imprimir condutas, regras, eventos e disputas de grupos sociais, configuram-se como artefatos. Bem ilustra essas categorizações a figura 3, acima apresentada, que seleciona os testemunhos do que vem a ser considerado brinquedo infantil e, para, além disso, a compreensão do que é "brincar" e "infância", ou seja, os símbolos escolhidos e como são entendidos determinam a conduta para tais práticas e representam grupos. Se por um lado o testemunho reconhece e reforçar artefatos, por outro lado, enfraquece e desdiz outros fenômenos (HALBWACHS, 2006).

Os artefatos, quando são apresentados em circunstâncias das mais diversas, podem provocar lembranças nos sujeitos, quer dizer, a capacidade de rememorar episódios vividos mesmo fora do contexto de quando e onde ocorrera a experiência. Portanto, a lembrança em Halbwachs (2006) não é entendê-la como uma ilusão ou um delírio. É vir à mente, de repente por um acaso, situações revividas e participadas pelo sujeito ou no contato com objetos que remetem a algo já vivenciado.

O reconhecimento identitário que tais artefatos produzem nos humanos é o que Halbwachs (2006) denomina memória coletiva. Acresce dela a relação com a noção de pertencimento de grupo e, por isso, é carregada de crenças e da legitimação de valores que incluem, segmentam ou excluem sujeitos.

A memória é o vivido reconfigurado, que sofre cortes, retalhos e atalhos. Parte do princípio que há coisas ou fatos que desejamos que permaneçam presentes e outros que queremos eliminar, deliberadamente ou não. Como é reconfigurada, elimina-se ou busca-se esquecer a negatividade de alguns episódios do vivido, enaltecendo os atributos de positividade, considerando-a aquilo que desejamos reforçar. Por isso, do passado é selecionado daquilo que queremos conservar, que mereça permanecer no presente e ser replicado, ganhando o estatuto de memória. Podemos dizer que a memória fundamenta o sujeito em suas relações identitárias, que são reconstruídas a partir de experiências vividas, mas também da dinâmica em virtude do poder que a identidade possui em se atualizar visando a sua permanência, reconhecimento e legitimação do grupo (ASSMANN, 2011).

Analisando os mercados, padrões, Deus e desigualdade, Apple (2003, p. 58) argumenta: "o 'outro' inspira medo". Refere-se a uma tentativa de fixar a tradição dos neoconservadores nos Estados Unidos da América (EUA). O debate estabelecido foi entorno do currículo escolar e do discurso direitista da tradição, que defende "a existência de um consenso social em relação ao que deve ser considerado de um saber legítimo e sobre superioridade cultural" (APPLE, 2003, p. 59). Tenta-se impor uma narrativa de uma sociedade estática, marginalizando outras culturas a serem contempladas no currículo escolar desse país. $\mathrm{O}$ medo do "estranho", segundo Apple (2003), é uma estratégia de impor vontades e valores sobre os "outros" e, para isso, um grupo agarra-se a um "límpido" e "perfeito" passado como forma de justificar a não inclusão do "outro" e impedir alterações na sociedade, num esforço de tentar cristalizá-la.

O interessante desse processo é perceber a nossa vã ilusão quanto à origem das ideias, como se fosse somente nossa quando, na verdade, são anteriores e, quiçá, posteriores a 
nossa existência. É como se déssemos voz ou fôssemos o eco de determinadas representações que nos governam. São reflexões, sentimentos e emoções que transmitimos, contudo, inspirados pelo grupo ao qual pertencemos. Nascemos em uma ordem que ora se fortalece e ora se renova. Trata-se de uma visão circular de cultura, que não tem ponto de partida ou de chegada. É um movimento constante e nos situamos e nos movemos em seus quadrantes. Halbwachs (2006) completa que, por mais que mudemos de local, de profissão, de família, não se rompe inteiramente com os laços que nos prendem aos nossos grupos antigos.

Debate também traçado por Latour (1994) em torno da concepção de "tempo" e que está associado à lógica da circularidade cultural. Baseando-se em Strauss, Latour (1994) argumenta a existência de duas nuances que envolvem a percepção de "tempo" no contexto dos humanos: "tempo histórico" e "tempo social". O primeiro é cronológico e diacrônico, delimitando as linhas do passado, presente e futuro. Já para o segundo, o tempo é sincrônico. Trata-se de uma visão circular e que está em permanente recomeço, permitindo a noção de um eterno presente. Decorre disso a dúvida em torno do que vem a ser o "tempo", pois nessa perspectiva assume um viés a-histórico e a-social.

Assim, passamos a compreender que há temporalidades, rompendo com a métrica alusiva à exclusividade de uma cultura sobre a outra, que determina onde e quando começa o tempo. A linearidade esconde os processos, os conflitos e a dinâmica da sociedade. Nessa perspectiva, não se pode compreender que as tradições são em si são cristalizadas, mas que possuem renovação em seu interior e cotidianamente.

Romper com a cristalização, ou até mesmo percebê-la de forma consciente, pode gerar no sujeito o processo de relativização da percepção de cultural, quiçá, gerando desprendimento da noção de hierarquização da cultura, ou seja, compreender a inexistência da superioridade ou inferioridade entre elas. Com isso, derroga-se a imagem de progresso e de culturas tidas como elevadas. Toda cultura emana de uma teia de (res)significados. Se por um lado a tradição quer estabelecer a perspectiva do grupo dominante, por outro, há o vício em tutelar "o outro" como se não tivesse condições de cuidar de si. Tornamos a vê-la como isolada e imutável. Contudo, essa descrição e registro é a captura de um momento particular com tempo, espaço, objetos e humanos delimitados e precisos. Disso produz-se um problema lógico: essa tentativa estranha de tornar o particular em geral, gerando outra noção falaciosa que é o estabelecimento de modelos de cultura (WAGNER, 2006).

Essa, sem dúvida, é uma questão de interesse da Ciência da Informação (Cl) quando desenvolve os seus estudos e práticas voltados para o registro e a sua representação. Essa postura remete a necessidade de materialização da informação, ou seja, esta enquanto sinônimo de documento (BUCKLAND, 2012). Nessa perspectiva, o espectro da memória precisa ser tangível, para que possa ser selecionada, organizada, representada, descrita, classificada, disseminada, recuperada, acessada, usada, avaliada e reconfigurada. É por isso que se estabelece a relação entre memória e informação: a segunda concretiza a primeira, transformando-a num produto físico. Tornar a memória passível de registro implica em algumas amarras e armadilhas, pois captura um momento constituído por humanos, não-humanos, contexto, fixando-o num tempo e espaço fixos e determinados. Se o mesmo evento ocorrer novamente, esse conjunto constituído não consegue ser reproduzido da mesma forma como se apresentou primeiramente. Daí repousa a armadilha: quando o pesquisador captura o momento e tenta modelá-lo, categorizá-lo e estabelecer predições. Essa concepção também produz no pesquisador uma eterna busca pelo registro dos fenômenos.

Do modo como é realizada a pesquisa social, é evidente que se trata do olhar do "outro" sobre o ser pesquisado. Wagner (2006) adota a concepção de "estranhamento", pois 
percebe que precisamos capturar, para além do momento de apreensão do ocorrido por meio dos sentidos e da interpretação, a diferença, o que ele nomina de necessidade epistemológica do "choque cultural" por parte do observador em relação "ao outro". Não se trata de analisar, no sentido de decompor as partes, mas de debruçar o olhar opondo-se ao já dito, ao já feito e ao já pensado e, por isso, lança a nominada sociologia imaginativa. Somos "inventores de cultura", pois construímos uma (res)significação do "outro" por meio de um conjunto/sistemas de significados que é nosso. Cristalizamos o "outro" na nossa linguagem e perspectiva, ou seja, o emolduramos. Delineamos e categorizamos o "outro" a partir de nossa percepção e escolha.

Essa purificação cultural existe em várias esferas sociais, o que inclui a acadêmica. Dessa cristalização, emerge também uma visão de ciência, que se institui por meio de parâmetros, a saber, a especificação dos objetos, a aplicação de metodologias, a formulação de teorias e leis e a testabilidade para que ao final se possa predizer e estabelecer modelos. Law (1994) critica a pretensa pureza da teoria política e social e oferece um caminho: a sociologia alternativa (ou imaginativa), que crítica diretamente à noção de formulações de leis para dar conta do complexo social. Isso reforça os nossos argumentos da incessante tentativa da dita "ciência social" de perspectiva positivista de emoldurar, modelar e prever o ser humano em suas práticas. O mundo e as suas coisas são imprevisíveis, mas o fazer da "ciência pura" tenta estabelecer a ilusão de uma "ordem natural". Essas percepções, aparentemente constantes e imutáveis acerca do real, produzem a formulação de leis por meio de uma lógica denominada indutiva. Frágil, pois basta uma única ação inversa do que se estabeleceu como sendo universal, a lei é refutada. Essa mesma lógica que se tenta aplicar as áreas vinculadas aos humanos, buscando uma ordem.

Law (1994) claramente argumenta que precisamos superar essa ordem, a noção de harmonia e a compreensão de arborização das ciências. Essa noção, deveras cristalizadora, ainda estabelece entre os saberes uma hierarquia, uma relação de subordinação e de superioridade. A estruturação atual das ciências incorpora essa artificialidade parcial e tendenciosa.

Sem dúvida essa é uma visão de memória e de informação que em seu cerne, ainda que não configure a intenção, ancora-se numa perspectiva física e, a depender do grau de comprometimento ideológico do pesquisador, reforce uma ideia de cristalização do outro e de imutabilidade cultural. De certo, analisamos como um sério risco e problema, pois tenta encobrir a dinamicidade social. Sempre foi assim e assim sempre será (LÖWY, 1994) gera a inércia e a comodidade, conduzindo os outros a pensarem e se portarem com indiferença em relação ao seu tempo e espaço.

Quando a $\mathrm{Cl}$ assume a postura física da informação, traz consigo uma concepção sobre o social, melhor explicando, uma visão de mundo. Percebemos que o problema não reside na conceituação ou na categorização dos processos sociais, mas as suas implicações sobre a concepção de social que imprime sobre o humano.

Law (1994) e outros estudiosos da sociologia alternativa (ou imaginativa) reforçam uma nova percepção, a do "entranhamento". Trata-se de outra perspectiva pautada na contraposição do dual e da fragmentação. Dessa compreensão, partilha a categoria de "agenciamento", que se refere à interação entre as pessoas e delas com os objetos/artefatos/adereços/tecnologias. Assim, Law (1994) aponta a lógica do "entranhamento" entre agentes e tecnologias. Sem interação, seríamos apenas corpos. A "teoria" da agência não se resume a simplesmente falar apenas sobre as pessoas, mas delas, das coisas e do seu entorno. Nessa perspectiva, os atores ou os agentes não têm necessariamente que ser pes- 
soas, podendo tratar-se de não-humanos. Essas relações e padrões recorrentes, incorporados, testemunhados, gerados e reproduzidos como parte do ordenamento das relações humanas e não-humanos. Acreditamos ser essa uma das estratégias que possa sinalizar uma reconfiguração da $\mathrm{Cl}$ entorno da memória e informação, posicionando-se frente à purificação.

\section{4 À GUISA DE CONCLUSÃO}

Partimos da premissa que escrever é um exercício mental, devendo primar pela clareza dos argumentos para que se estabeleça a conexão com o leitor: este não pode ser "martirizado pelo efeito narcótico de períodos longos e enviesados, sem pensamento algum. [...] Não há nada mais fácil do que escrever de tal maneira que ninguém entenda" (SCHOPENHAUER, 2007, p. 82-83). Baseando-nos em Schopenhauer (2007), entendemos que a arte da escrita prescinde a concisão, a precisão, a expressividade e a clareza do conteúdo, primando pela originalidade e objetividade.

Os artefatos, assim como a própria linguagem, promovem nos humanos fenômenos arraigados em crenças e em valores nominados, segundo Halbwachs (2006), de memória coletiva, que possuem o poder de incluir, segmentar ou excluir sujeitos. Essa memória pode se materializar em práticas de cristalização cultural, com potencial de reconfigurar ou de reproduzir o vivido. O passado sempre presente; eis a problemática.

Reforçar práticas culturais e sociais envolve o enaltecimento positivo de algo que se deseja avigorar, selecionando e conservando a noção proferida por grupos de interesse, tentando replicar ou permanecer no presente recortes cirúrgicos do passado. Esse movimento é tão marcante e forte que ganha o estatuto de memória. As experiências vividas são fundamentais no processo de (res)siginificação e, por isso, fundamental confrontá-la à cristalização da cultural, como estratégia dinâmica e contrapositiva (ASSMANN, 2011).

Com os avanços da biologia e física, põe em xeque-mate essa divisão entre orgânico e inorgânico e entre humanos e não-humanos, haja visto, por exemplo, as teorias defendidas por Maturana e Varela (2004), que se voltam para um uno, destoando da perspectiva dual de mundo. Atribui aos não-humanos características que antes eram particular do homem, tal como consciência, comunidade e, fenômenos mentais.

Nessa ótica, novos campos do saber, que não abraçam o atual modelo dominante de ciência, incluem categorias como: liberdade, processo, contexto, historicidade e autodeterminação. Contudo, somente relatar que há superação entre ciências sociais e naturais é permanecer no lugar comum. É preciso apontar saídas de análise. Uma delas é perceber que as ciências naturais são, antes de tudo, sociais. São produzidas, ditadas, interpretadas, analisadas, descritas pelo humano, com os seus limites e potencialidades. Segundo Santos (1996, p. 43), "à medida que as ciências naturais se aproximam das ciências sociais estas se aproximam das humanidades". E o autor supra, continua afirmando: "o sujeito, que a ciência moderna lançara na diáspora do conhecimento irracional, regressa investido da tarefa de fazer erguer sobre si uma nova ordem científica" (SANTOS, 1996, p. 43).

Alguns episódios ocorridos e citados ao longo texto e das figuras apresentadas fizeram-nos refletir e questionar acerca da representação da cultura no contexto da Ciência da Informação $(\mathrm{Cl})$. Pensar na informação como materialidade da memória reforça a sua percepção física. Para além da inocente prática de registro, a cristalização se apresenta como um posicionamento em torno do tipo de sociedade e de humano; de reprodução do passado. Isso pode gerar percepção cristalizadora da ciência e, por isso, o quão pertinente partir 
do real como problema a ser estudado, principalmente, no campo das relações sociais, o que envolve os fenômenos como a memória e a cultura.

\section{REFERÊNCIAS}

ASSMANN, A. Espaços da recordação: formas e transformações da memória cultural. Campinas: UNICAMP, 2011.

APPLE, M. W. Educando a direita: mercados, padrões, Deus e desigualdades. São Paulo: Cortez, 2003.

AVPRODUCTIONS Artística. Se você se lembra disso... [S. I.: s. n., 21--]. Disponível em: $<$ https://www.facebook.com/photo.php?fbid=569070489770573\&set=a.467254879952135. 112548.467077746636515\&type=1\&theater>. Acesso em: 20 ago. 2019.

AZEVEDO NETTO, C. X. Informação e memória: as relações na pesquisa. Revista História em Reflexão, Dourados, UFGD, v. 1, n. 2, p. 1-19, jul./ dez. de 2007.

BUCKLAND, M. What kind of science can Information Science be? Journal of the American Society for Information Science and Technology, v. 63, n. 1, p. 1-7, 2012.

ESTILO Próprio By Sir. Sou de uma época... [S. I.: s. n., 21--]. Disponível em: <https://www.facebook.com/EstiloProprioBySir/photos/a.503619799664350.130338.50361 7752997888/691394377553557/?type=1\&theater>. Acesso em: 20 ago. 2019.

FOUCAULT, M. A arqueologia do saber. Rio de Janeiro: Forense Universitária, 1987.

FOUCAULT, M. A ordem do discurso. São Paulo: Loyola, 2000.

FOUCAULT, M. Vigiar e punir: nascimento da prisão. Petrópolis: Vozes, 2002.

GAARDER, J. O mundo de Sofia: romance da história da filosofia. São Paulo: Companhia das Letras, 1995.

HALBWACHS, M. A memória coletiva. São Paulo: Centauro, 2006.

LATOUR, B. Jamais fomos modernos: ensaio de Antropologia simétrica. Rio de Janeiro: 34, 1994.

LAW, J. Organizing modernity. Oxford: Blackwell, 1994.

LÖWY, M. Visões sociais de mundo, ideologias e utopias no conhecimento científico-social. In: As aventuras de Karl Marx contra o Barão de Münchhausen. São Paulo: Cortez, 1994.

MATURANA, H; VARELA, F. A árvore do conhecimento: as bases biológicas do conhecimento humano. São Paulo: Palas Athena, 2004. 
MC GUI. Isso sim, se chama infância... [S. I.: s. n., 21--]. Disponível em: <https://www.facebook.com/McGuiOficial1/photos/a.394452843943377.98343.394352037 286791/482880888433905/?type=1\&theater>. Acesso em: 20 ago. 2019.

MINTZ, S. W. Cultura: uma visão antropológica. 2010. Disponível em: <http://www.redalyc.org/articulo.oa?id=167013403010>. Acesso em: 20 ago. 2019.

OLIVEIRA, C. Participação em ato pró AI-5 isola Bolsonaro ainda mais e cresce oposição ao governo. São Paulo: Brasil de Fato, 20 abr. 2020. Disponível em:

<https://www.brasildefato.com.br/2020/04/20/repudio-a-participacao-de-bolsonaro-emato-pro-ai-5-deixa-presidente-mais-isolado>. Acesso em: 10 maio 2020.

O GLOBO. Bolsonaro volta a apoiar ato antidemocrático e diz que não vai mais 'admitir interferência'. Brasília: G1, 03 maio 2020. Disponível em: <https://g1.globo.com/df/distritofederal/noticia/2020/05/03/manifestantes-fazem-carreata-pro-bolsonaro-na-esplanada-dosministerios-em-brasilia.ghtml>. Acesso em: 10 maio 2020.

ORLANDI, E. P. Discurso e leitura. São Paulo: Cortez, 2001.

ORLANDI, E. P. Interpretação: autoria, leitura e efeitos do trabalho simbólico. Petrópolis: Vozes, 1998.

POMBO, O. Epistemologia da interdisciplinaridade. In: SEMINÁRIO INTERNACIONAL INTERDISCIPLINARIDADE, HUMANISMO, UNIVERSIDADE. Porto, 2003. Anais [...]. Porto, 2003. p. 129. Disponível em:

<http://www.uesc.br/cpa/artigos/epistemologia_interdidciplinaridade.pdf>. Acesso em: 11 abr. 2019.

SANTOS, B. S. Um discurso sobre a ciência. Porto, Portugal: Afrontamentos, 1996.

SCHOPENHAUER, A. A arte de escrever. Tradução Pedro Süssekind. Porto Alegre: L\&PM, 2007.

UNESCO. Relatório sobre ciência 2010: o atual status da ciência em torno do mundo. [S. I.: s. n.], 2010. Disponível em: <https://unesdoc.unesco.org/ark:/48223/pf0000189883_por>. Acesso em: 20 ago. 2019.

WAGNER, R. A invenção da cultura. São Paulo: Cosac \& Naify, 2006. 